\title{
Narrativas: as falas da experiência - colaboração para a formação de professores no mundo lusófono
}

\author{
Narratives: the discourse of experience - \\ collaboration to formation of teachers in the \\ Lusophone world
}

Narratives: Les discours de l’expérience

Isis Flora SANTOS

\begin{abstract}
RESUMO
Busca compreender os saberes e fazeres docentes presentes nas narrativas das professoras alfabetizadoras do Colégio de Aplicação da Uerj. Os saberes e fazeres presentes nas falas das professoras que são tómadas como objetivo de reflexão e análise. Essa opção se deu por acreditar que o espaço de sala de aula pode ser um centro de pesquisa e de formação docente. A opção teórica pela Investigação Narrativa possibilitou ver as falas como fonte e como método de análise. Sendo um movimento que nos leva a uma explicação e re-explicação dos fatos narrados. Como fonté principal deste trabalho, que subsidiou a análise dos saberes e fazeres' das docentes, tem-se o conjunto de entrevistas realizadas com as professoras alfabetizadoras.

Palavras chave: Narrativa - alfabetização - saberes e fazeres docentes

ABSTRACT

The research tries to comprehend the knowledge and practices that were used by UERJ staff. Teachers realized that the classroom could be a center of apprenticeship. The theoric option the Narrative Investigation allowed to see the speech as a mean of studies. This work was basead on an amount of researches that were made with the discourse helped to see that shows the institution trajectory. The discourse helped to see that the staff comprehend their own work and the process of reading and writting lived by their students.
\end{abstract}


Index terms: Narrative - reading and writing process - knowledge and practices of teachers

\title{
RESUME
}

Cherche de comprendre ce que les enseignants connaissent et font dans les récits de l'alphabétisation des enseignants du Collège de l'application de UERJ. Les connaissances et le discours de ces enseignants sont pris comme l'objectif de réflexion et d'analyse. Cela s'est passé grâce à la conviction qu'ils ont eu, que la superficie de la salle de classe peut être un centre de recherche et de formation des enseignants. L'option théorique pour "Investigação Narrativa" a rendu possible la parole en tant que source et méthode d'analyse. Comme un mouvement qui nous conduit à une explication et une re-interprétation des faits. En tant que source de travail, qui a subventionné l'analyse de la connaissance et des enseignants, il a tous les entretiens avec les alphabétiseurs.

Mots-clés: Narrative, alphabétisation, savoir e travail des enseignants

\section{INTRODUÇÃO}

\author{
Os sujeitos se constituem como tais à medida \\ que interagem com os outros, sua consciência e \\ seu conhecimento de mundo resultam como \\ "produto" deste mesmo processo. \\ Neste sentido, o sujeito é social(...) \\ Também não há sujeito dado, pronto, que entra \\ na interação, mas um sujeito se completando e \\ se constituindo nas suas falas. \\ Wanderley Geraldi
}

Este artigo é parte integrante da minha dissertação de mestrado "Narrativas, experiências, saberes e fazeres docentes: o que nos falam as professoras alfabetizadoras do CAP-UERJ" e, buscou pesquisar os saberes e fazeres presentes no cotidiano alfabetizador das salas de aula do Colégio de Aplicação da Universidade Estadual do Rio de Janeiro (CAP-UERJ). 
Ao longo da pesquisa, realizei entrevistas com quatro professoras alfabetizadoras. A escolha destas professoras se deu por elas trabalharem diretamente com as crianças das séries iniciais do Ensino Fundamental.

As falas das professoras me permitiram puxar fios e aos poucos ir tecendo a narrativa. Essa situação é percebida à medida que se acredita que a Investigação narrativa é um movimento de colaboração que nos leva a uma explicação e re-explicação dos fatos narrados. Sendo o pesquisador o responsável por garantir que todas as vozes estejam presentes na ação investigativa (CONNELLY y CLANDININ, 1995).

Segundo os autores, a Investigação narrativa é uma das formas mais apropriadas de se trabalhar com as situações escolares, pois as narrativas de vida podem dar sentido as práticas analisadas, no caso deste texto, através das falas das professoras.

Nesse sentido, Bakhtin (2003) também é muito importante neste trabalho, em virtude de sua concepção de linguagem, enunciado e palavra, estreitamente relacionada ao contexto sócio-histórico. Para o filósofo/lingüista/pensador, todo enunciado carrega, ao mesmo tempo, uma capacidade responsiva e uma incompletude: ele é construído, proferido por sujeitos em determinados contextos sócio-ideológicos e carrega um potencial de resposta do outro, além de ser "incompleto", pois não se constitui como algo acabado, pronto e definido.

As entrevistas foram realizadas no ambiente de trabalho das professoras, mais precisamente em suas salas de aula. Parti para a realização das mesmas com algumas questões que seguiam um roteiro préestabelecido, mas, à medida que as conversas transcorriam, suas falas tornaram-se "conversas" vivas e, embora a direção pré-estabelecida existisse, esta não caracterizou engessamento dessas entrevistas enriquecidas por narrativas e despertava em mim, novas perguntas e novas reflexões. 
As professoras optaram por serem identificadas no corpo do texto, fato que para o estudo foi muito importante, pois acredito que "o sujeito encarnado $^{1}$ participa de uma dinâmica criativa de si mesmo e do mundo com que ele está em permanente intercâmbio" (NAJMANOVICH, 2001, p. 23). Ao trabalhar com o princípio de que o outro é um sujeito ativoparticipante da ação pesquisadora- e o seu nome marca a sua participação enquanto ser social e profissional, com a história própria de cada um e ao questionar a possibilidade de utilizar seus nomes verídicos uma das professoras me disse que não via motivos para não ser identificada, já que assume o que fala e faz, ou seja, é um sujeito de seu tempo.

As narrativas trazem um pouco do que as professoras acreditam ser um trabalho alfabetizador, dos fazeres e saberes construídos ao longo do processo de formação experienciado, individual e coletivamente e, também, nas expectativas relativas ao processo de ensino vivenciado por seus alunos e alunas.

Cada uma das professoras possui um jeito particular de olhar e vivenciar a realidade experenciada, em parte, por terem percursos profissionais diferentes e, também, porque cada uma delas experiencia de forma muito própria os acontecimentos surgidos no dia-a-dia da sala de aula. Por mais que compartilhem de idéias comuns, a multiplicidade e diversidade de saberes e fazeres é o tempero que enriquece o diálogo entre elas.

É pela narrativa que as professoras se descobrem e se deixam conhecer - dimensão formativa, que faz da narrativa um espaço de diálogo e articulação entre saberes e fazeres (PEREZ, 2003, p.139).

Compreendo a narrativa como um processo coletivo, de troca e crescimento profissional composto por diversas vozes:

\footnotetext{
1 Trabalhar com o conceito de sujeito encarnado é acreditar que os indivíduos agem e interagem com os acontecimentos e o fazem de maneira própria e única, pois esta intervenção está diretamente ligada a experiência pessoal e social de cada um dos sujeitos.
} 
(...) La investigación narrativa es un processo de colaboración que conlleva una mutua explicación y reexplicación de historias a medida que la investigación avanza. En el processo de empezar a vivir la historia compartida de la investigación narrativa, el investigador tiene que ser consciente de estar construyendo una relación en la que ambas voces puedan ser oídas(...)Las dos narraciones, la del participante y la del investigador, se convierten, en parte, gracias a la investigación, en una construcción y re-construcción narrativa compartida (CONNELLY y CLANDININ, 1995, p.21, 22, 23).

$\mathrm{Na}$ construção dessa concepção de narrativa com a qual trabalho, entendi, a partir de Vygotsky (1999) e Bakhtin (2003), que a palavra é o elo de ligação entre o eu, o outro e o mundo. As palavras vêm carregadas de sentidos construídos histórica e culturalmente, trazendo consigo os modos singulares que o sujeito tem de estar no mundo e de compreendê-lo.

A palavra por si só, nada diz, ecoa num vazio, apenas dentro da enunciação de um discurso, ela se reveste de todo um significado pertinente ao contexto sócio-histórico no qual é anunciada, além de vir embebida da entonação própria de cada sujeito (BAKHTIN, 2003). Por isso, acredito que a análise das narrativas pode apontar, dentro de um contexto, como as professoras entrevistadas compreendem o processo de alfabetização, ligado diretamente às ações docentes praticadas por elas no cotidiano escolar.

\section{SABERES E FAZERES EM DIÁLOGO}

Ao ser entrevistada, a professora Olga resgata o processo de incorporação da CA na escola, que ocorreu há 19 anos, mas que em seu discurso permanece vivo e atual. Como Ribeiro (2005, p.165) nos fala, há a permanência no tempo "da força do passado".

A professora Olga trabalha no Colégio de Aplicação da Uerj há 21 anos, desde antes da escola abrir a sua primeira classe de alfabetização, motivo pelo qual experienciou o processo de implantação da alfabetização 
no CAp-Uerj. Seu relato, bastante interessante, revela o envolvimento com a função exercida, por ela, na escola: professora das séries iniciais do Ensino Fundamental.

[...] em 1987 nós tivemos a primeira turma que entrou para a classe de alfabetização por sorteio. [...], [antes de 1987 o ingresso no CAp só acontecia por prova na $1^{a}$ série e na $5^{a}$ série, hoje o ingresso acontece por sorteio na CA e prova para a $5^{a}$ série] Exatamente porque as crianças faziam pré-vestibular para entrar para essa escola com 6, 7 anos de idade e na verdade entravam crianças que tinham feito cursinho, esses cursinhos que havia por aí, pela Tijuca principalmente, preparando as crianças para entrarem nessa escola. Quer dizer aos 7 anos de idade eles estavam vivendo o que se vive aos 17 ou 18 anos e nós mudamos isso. Revertemos esse quadro. Acabou o concurso para as séries iniciais e só a partir daí começou a ter o sorteio público, que é muito mais democrático. Entram crianças de todos os níveis sociais e de todos os níveis de conhecimento. Nós recebíamos crianças já alfabetizadas que vinham de escolas particulares e, às vezes, de escolas públicas mesmo, que já chegavam com muito conhecimento, de escrita e de língua escrita, também foi assim, uma mudança radical na nossa metodologia porque a gente viu que não conseguia mais trabalhar como a gente trabalhava antes. E, já trabalhávamos de uma forma avançada em relação as outras escolas, mas a gente viu também que aquilo não dava certo, que precisávamos estudar, inventar uma outra metodologia, criar uma outra metodologia para essas turmas que vinham tão, tão, tão heterogêneas, porque a gente sabe que todas as turmas são heterogêneas, né, mas quando faziam concurso, a princípio, parecia que nivelava um pouco, na verdade não é isso, mas parecia, dava essa impressão. Realmente chegavam crianças com muito conhecimento, que eram crianças que faziam cursos, iam muito a teatro, a cinema, que tinham muitos livros, eram de outro nível também, uma outra classe social que entrava na escola. A partir de então[referindo-se ao sorteio na CA] nós tivemos uma heterogeneidade em todos os níveis, o que foi muito bom, porque fez a gente também parar, pensar, refletir no nosso projeto político pedagógico e nós mudamos. Naquela época, houve a criação na escola de um núcleo de Psicopedagogia. Eu era uma das professoras do núcleo. A gente ficava 
depois da hora estudando, discutindo e a Alice que era a outra professora também que começou com a CA, [...] ela já está aposentada [...] mas nós duas é que pegamos as primeiras turmas de Ca e de $1^{o}$ série e mudamos toda a metodologia. Começamos a estudar Piaget, depois Vygotsky, fomos procurar um curso fora, uma supervisão fora da escola. Tínhamos discussão na escola uma vez por semana, mas aquilo não estava dando conta e fomos estudar a teoria mais a fundo com uma supervisão fora. A gente pagava essa supervisão, à noite. Foi assim um ano de bastante sacrifício, mas que valeu a pena, porque quando a gente tem o desejo de mudar a gente tem que passar por alguns obstáculos tem que vencer, não tem como. Então foi um ano de muito estudo, e a partir daí a gente continuou participando de seminários, estudando muito, estudando na escola também. Ficamos mais voltadas mesmo para pegar os anos iniciais, somos alfabetizadoras por paixão, por escolha, eu acho que isso é fundamental, tudo que a gente escolhe na vida é o que a gente realmente tem o desejo de fazer e fazer bem, é o que a gente procura fazer. Eu acho que se a gente tem esse desejo já é um passo para o sucesso (professora Olga, 25/07/2006).

Nessa narrativa percebemos o envolvimento da professora com o colégio e com o processo de ensino e aprendizagem da linguagem escrita. Não é por acaso que afirma: "Somos alfabetizadoras por paixão, por escolha" e "isso é fundamental". Além disso, deixa claro seu desejo em realizar um trabalho alfabetizador que acredita ser o melhor para as crianças. Em outro momento, fala que considera o Cap "realmente a melhor escola do Rio de Janeiro. Sou fã número 1[...]".

Mas, a paixão ou a "vocação" não bastaram. Foi necessário também, mais empenho, dedicação e, sobretudo estudo, um mergulho na teoria para se repensar a prática. $\mathrm{O}$ contexto de antes/depois, contrapondo a situação dos alunos que ingressavam outrora (curso e pré+concurso) ao sistema de ingresso atual (sorteio), fez surgir um questionamento: por que o trabalho realizado anteriormente com as crianças que entravam por concurso não "dava mais conta" de garantir a aprendizagem? 
A própria professora nos sinaliza a resposta: "Realmente [naquele tempo do concurso]chegavam crianças com muito conhecimento, que eram crianças que faziam cursos, iam muito a teatro, a cinema, que tinham muitos livros, eram de outro nível também, uma outra classe social que entrava na escola" (professora Olga, 25/07/2006).

Ao fazer uso do sorteio, o CAP-Uerj abre a possibilidade para as crianças das classes populares ingressarem nesse espaço escolar. Com isso, surgem outros modos de aprender, outras lógicas e outros saberes que chegam com essas crianças.

Como Garcia (2004) discute, as crianças de classe popular e afrodescendentes são "oriundas de uma cultura predominantemente oral" e ao entrarem na escola se deparam com outra realidade. Esse aluno e essa aluna "se vê [vêem] exposto [expostos] à transmissão escrita e numa variedade lingüística até então desconhecida para si” (p.24).

Regina Leite Garcia (2004) nos fala que precisamos estar atentas à origem social e cultural dessas crianças, pois os estudantes das classes populares, de um modo geral, antes de entrarem na escola vivem em um "universo" que parece privilegiar a cultura oral. A linguagem escrita pouco aparece. São crianças que quase não têm acesso ao teatro, ao cinema, à exposição e aos cursos variados - modos de ser e estar no mundo valorizados pelas escolas, de um modo geral e, especificamente pelo CApUerj.

Como a professora Olga nos diz: "eram de outro nível [...] uma outra classe social que entrava na escola." Foi preciso, então, repensar essa prática alfabetizadora e tentar fazer de outro jeito "porque a gente viu que não conseguia mais trabalhar como a gente trabalhava".

Era preciso estar atenta às manifestações dos saberes das crianças das classes populares, valorizando-os e deles partindo de modo a garantir que todos os alunos e alunas aprendessem e não apenas os que se 
"sintonizam" com os saberes valorizados pela escola. É bastante comum presenciarmos no dia-a-dia da sala de aula o que a autora nos diz:

Ora, se o discurso da escola é de que a ela caberia a socialização do conhecimento (...) tudo que não fosse aprendido na escola, não teria valor. (...) Logo, aqueles e aquelas que portassem um outro tipo de conhecimento, adquirido no cotidiano de suas vidas, no trabalho, em suas lutas por sobrevivência, nenhum valor teriam, nenhum crédito mereceriam, nenhum direito poderiam ter garantido, pois nenhum mérito teriam conquistado. (GARCIA, 2004, p. 14).

O aprender e o ensinar ocorrem em diferentes espaços e tempos: na rua, com vizinhos, na família, entre amigos, navegando na internet e, também, na escola. Não podemos mais acreditar que o [...] estatuto do conhecimento passa pela escolarização, isto é, que a escolarização é constitutiva do conhecimento. O que quer dizer: "quem não vai a escola não possui conhecimentos" (SMOLKA, 2003, p.31).

As crianças "a partir de suas múltiplas experiências de vida, tecem conhecimentos, criam lógicas e formas de pensar, resolvem problemas" (ARAÚJO, 2004, p.141). Mesmo os alunos (as) que vêm de uma cultura mais oralizada, como as crianças da classe popular, possuem saberes tão importantes quanto os valorizados pela escola. Mas, como garantir que todas as crianças aprendam a ler e a escrever e não apenas as que vivenciavam fora da escola experiências com a linguagem escrita valorizadas e legitimadas pela escola?

A professora nos disse:

A partir de então [referindo-se ao sorteio na CA] nós tivemos uma heterogeneidade em todos os níveis, o que foi muito bom, porque fez a gente também parar, pensar, refletir no nosso projeto político pedagógico e nós mudamos. Naquela época, houve a criação na escola de um núcleo de Psicopedagogia. Eu era uma das professoras do núcleo. A gente ficava depois da hora estudando, discutindo e a Alice que era a outra 
professora também que começou com a CA, [...] ela já está aposentada [...] mas nós duas é que pegamos as primeiras turmas de Ca e de $1^{o}$ série e mudamos toda a metodologia. (professora Olga, 25/07/2006)

Incomodadas com a própria prática alfabetizadora a professora Olga e sua colega se puseram no movimento de estudar, discutir e aprender. Sabiam que o "amor" e a intuição apenas não são suficientes na construção de um fazer pedagógico comprometido com o aprender de todos os alunos e alunas. Não podemos agir somente por intuição ou "amor". Paulo Freire, há muito nos diz, que "conhecer não é, de fato, adivinhar, mas tem algo que ver, de vez em quando, com adivinhar, com intuir" (FREIRE, 1997, p. 51). No entanto, precisamos ter uma base teórica consistente e uma constante problematização, e isso só é possível com estudo e troca entre os pares. Volto à obra de Paulo Freire que, insistentemente, em seus escritos, nos lembra:

$\mathrm{Na}$ formação permanente dos professores, o momento fundamental é o da reflexão crítica sobre a prática. É pensando criticamente a prática hoje ou de ontem que se pode melhorar a próxima prática. O próprio discurso teórico, necessário à reflexão crítica, tem de ser de tal modo concreto que quase se confunda com a prática (FREIRE, 1997, p.44, 45).

A professora Olga e sua colega buscam uma forma de alfabetizar "melhor", de aprimorar a sua próxima prática, se empenham, ficam "depois da hora estudando, discutindo", repensando esse fazer alfabetizador, pois acreditam que todas as crianças são capazes de aprender. Ficavam incomodadas em saber que, em suas turmas, existiam crianças que não aprendiam a ler e escrever no tempo escolar de 2 anos. Essas professoras, no processo de aprender a melhor alfabetizar, vivenciaram o apontado por Regina:

E ela [a professora] se põe a investigar o que acontece em sua sala de aula e a se fazer perguntas a partir do que 
capta do emaranhado de fios da multiplicidade de redes que tecem o cotidiano escolar. Vai se tornando uma professora-pesquisadora de sua própria prática, processo no qual vai produzindo novas teorias sobre o complexo processo de ensinar e aprender. A teoria se atualiza, enriquecendo-se com as explicações que emergem da pesquisa da prática. A prática se transforma com a incorporação das novas teorizações resultantes da pesquisa.(GARCIA, 2004, p.25)

No seu cotidiano, em suas salas de aula, essas professoras buscavam através de acontecimentos, fatos, relatos, o movimento da aprendizagem. Buscam, na articulação entre a prática e a teoria a compreensão do que realizavam, no dia-a-dia, com as crianças: "começamos a estudar Piaget, depois Vygotsky, fomos procurar um curso fora, uma supervisão fora da escola" (Olga, 2006).

Nesse movimento contínuo, essas professoras repensam e reconstroem a própria prática, tornam-se professoras pesquisadoras de seu fazer pedagógico.

(...) o conhecimento profissional do docente é, evidentemente, um conhecimento especializado sempre provisório, parcial e emergente. Se apóia na reflexão compartilhada e na compreensão situacional, pode ser considerado o melhor conhecimento disponível para essa prática concreta, porque foi gerado não apenas sobre a análise da situação concreta, utilizando o conhecimento público disponível, como porque também é o resultado da interação entre a compreensão e a ação que mutuamente se potenciam (PÉREZ GOMEZ, 2001, p.191).

Esse movimento é crucial para a formação docente e também para a aprendizagem dos estudantes. É preciso garantir que as crianças, principalmente as das classes populares, possam ter acesso à aprendizagem da linguagem escrita na escola, pois os números do fracasso escolar, no nosso país, continuam altos. Segundo os últimos resultados do SAEB (2003), o Brasil tem 33,3\% das crianças com distorção série/idade só no 
primeiro segmento do Ensino Fundamental, no segundo segmento chega a 40,6\% e no Ensino Médio 45,8\%. Em 2003, 30,1\% das crianças que ingressavam na $1^{\mathrm{a}}$ série ficavam reprovadas. Sendo o $12^{\circ}$ país da América Latina no ranking da repetência segundo pesquisa realizada pela Unesco como falado anteriormente.

Infelizmente, a discussão sobre a prática pedagógica, a prática alfabetizadora em algum momento se enfraqueceu na Instituição. Durante todo o período em que estive no CAp, como professora, não houve uma discussão acerca da teoria que subsidia a prática alfabetizadora realizada na escola e, ao entrevistar as professoras, percebi que as trocas acontecem em pequenos subgrupos, através de ações individuais.

As demais professoras entrevistadas Jonê, Rita e Jaqueline mantêm um vínculo de amizade bastante significativo. Essa relação de amizade foi percebida ao longo das entrevistas e, principalmente, na cumplicidade entre elas. Nas falas estão presentes as personalidades individuais, as posturas pessoais e a busca delas por um trabalho coletivo, que vai se construindo coletivamente à medida que as interações se dão no cotidiano escolar. Professoras pesquisadoras de sua própria prática, que procuram discutir e refletir sobre as suas atitudes, fazeres e saberes docentes. Como nos diz Paulo Freire:

Fala-se hoje, com insistência, no professor pesquisador. No meu entender o que há de pesquisador no professor não é uma qualidade ou uma forma de ser ou de atuar que se acrescente à de ensinar. Faz parte da natureza própria da prática docente a indagação, a busca, a pesquisa. O que se precisa é que, em sua formação permanente, o professor se perceba e se assuma, porque professor, como pesquisador (1997, p.32).

O diálogo, como diz Nóvoa (1995), é saudável, enriquecedor, podendo ser a base para as narrativas profissionais dessas professoras. À medida, que elas se abrem para a discussão em grupo, compartilham seus 
saberes e não-saberes, tornam possível a reflexão sobre determinadas questões que precisam ser mais elaboradas, pensadas e discutidas, a partir de outros pontos de vista (SAMPAIO, 2003, p.260).

[...] É uma escola que tem algumas características específicas, mas ela tem todas as contradições que têm nas outras escolas, ou parte dessas contradições. Então, nós tentamos que na primeira série haja uma certa unidade de trabalho, isso é favorecido à medida que nós temos relações pessoais muito boas. Então eu, Jonê e Rita, [...] temos relações pessoais muito boas, isso favorece uma certa confiança, para que o trabalho tenha uma certa unidade e a gente possa planejar com tranqüilidade, se abrir para ouvir o outro. [...] Então, se eu não tenho confiança em uma professora dificilmente eu vou me abrir para essa professora pra dizer as minhas dúvidas, das minhas inseguranças, a tendência é que a gente crie um espaço mais burocrático do que de fato de planejamento. Como há essa relação afetiva e de amizade entre nós três, mesmo quando nós não sentamos para planejar, a gente consegue de alguma forma trocar entre a gente [...] eu mandei um bilhetinho pra Jonê e pra Rita perguntando sobre uma atividade e elas responderam, então há esse espaço. Não vou dizer que há com todas as professoras, isso não é com todas, mas a gente tenta realizar. [...] As reuniões de planejamento acontecem muito pouco, as reuniões em que nós nos encontramos são muito mais por conta de atividades administrativas, questões administrativas do que propriamente pedagógicas, como em boa parte das escolas. (professora Jaqueline, 24/11/2005)

E complementando a opinião da professora Jaqueline, sua colega, indica:

[...]É bom a gente ter esse grupo porque é essa discussão que me alimenta. Refletir sobre o trabalho é que o redimensiona. $O$ trabalho que a gente tem desenvolvido aqui tanto na alfabetização como na primeira série, com as especificidades de cada uma, ele tem sido voltado muito para o trabalho com a leitura e com a escrita (professora Rita, 01/12/2005). 
As professoras nos sinalizam ser necessário a existência de um espaço no qual possa-se confiar na colega para poder, de fato, falar sobre suas dúvidas e angústias. A existência da confiança e a afetividade podem ser um facilitador para a circulação das idéias, e a sua falta um entrave. $\mathrm{O}$ vínculo afetivo favorece o pensar junto, o aprender (e o ensinar) com o outro. As professoras - Rita, Jonê e Jaqueline - são amigas, conversam, trocam conselhos e experiências profissionais. Aquilo que vivem, na escola, confirma o que nos diz Sampaio nas investigações realizadas com outro grupo de professoras alfabetizadoras: "Um vínculo baseado na confiança, cuidado e respeito, foi se constituindo, ao mesmo tempo em que constituía o grupo, possibilitando o aprendizado, as trocas e o compartilhamento das idéias" (SAMPAIO, 2003).

Por outro lado, esse realce desvela, também, a ausência de discussão coletiva, "as reuniões acontecem muito pouco, as reuniões em que nós nos encontramos são muito mais por conta de atividades administrativas [...] do que propriamente pedagógicas". As professoras anunciam a necessidade de um espaço legitimado pela escola para que as trocas e encontros de estudo possam de fato acontecer. A professora Jaqueline conta uma das alternativas utilizadas por elas para driblar essa situação:

Como há essa relação afetiva e de amizade entre nós três, mesmo quando nós não sentamos para planejar, a gente consegue de alguma forma trocar entre a gente: Ah... eu fiz hoje. Eu mandei um bilhetinho pra Jonê e pra Rita perguntando sobre uma atividade e elas responderam, então há esse espaço (professora Jaqueline, 24/11/2005).

Será que, de fato, há esse espaço? O Cap-Uerj oferece às professoras a possibilidade de trocar idéias e de estudar em grupo? As falas evidenciam que esse movimento de compartilhar idéias e trocar experiências, hoje, depende muito mais da iniciativa das professoras que buscam alternativas viáveis do que da escola que, pelo que dizem, não vem 
garantindo espaços e tempos de discussão, estudo e planejamentos coletivos.

Espaços tão importantes de construção, pois são nessas trocas e discussões, que as práticas alfabetizadoras realizadas, cotidianamente na escola tornam-se objeto de reflexão, análise, estranhamento - processo necessário para a construção permanente de novos conhecimentos. "Refletir sobre o trabalho é o que o redimensiona" (Professora Rita, 2005), é o que garante a discussão, dando condições a esse grupo de rever conceitos “melhorar a próxima prática" (FREIRE, 1997, p.44).

Ao referir-se ao conceito de alfabetização e ao que acredita ser o ensino realizado, hoje, no CAp-UERJ a mesma professora nos diz:

[...] Não tem cartilha, não tem lançamento de palavra chave, tem uma busca de criar na escola, de estabelecer na escola um espaço que as crianças possam pensar sobre a linguagem e a escrita, produzir linguagem escrita desde o início do ano, dos primeiros dias de aula, produzir atividades que tenham função social, as propostas de escrita têm como pré-requisito, para estar na sala de aula ter alguma função real, uma função social [...] (professora Jaqueline, 24/11/2005).

As palavras "criar" e "pensar" nos remetem a uma prática alfabetizadora pautada na construção do conhecimento com atividades instigadoras abrindo possibilidades para que os alunos e alunas, "possam pensar sobre a linguagem e a escrita, produzir linguagem escrita desde o início do ano", a partir de atividades que possuam "função real" e "função social".

A concepção da professora Jaqueline é confirmada pelo que é discutido por Smolka (2003),

A criança pode escrever para si mesma, palavras soltas, tipo lista, para não esquecer; tipo repertório, para organizar o que já sabe. Pode escrever, ou tentar escrever um texto, mesmo fragmentado, para registrar, narrar dizer...Mas essa escrita precisa ser sempre 
permeada por um sentido, por um desejo, e implica ou pressupõe, sempre, um interlocutor. (p.69)

Pude perceber durante a realização das entrevistas que as salas de aula da CA e $1^{\mathrm{a}}$ série são ambientes alfabetizadores, "em que há uma cultura letrada, com livros, textos digitais ou em papel, um mundo de escritos que circulam socialmente" (TEBEROSKY, 2005). Materiais expostos com o objetivo de instigar os alunos e alunas, agindo como um provocador da aprendizagem.

Ressaltamos, conforme diz Araújo (2004), "que não existe um ambiente universal" capaz de atender a todas "as necessidades de qualquer criança, em qualquer tempo e lugar”. Esses espaços estão atrelados ao momento histórico e social no qual são criados, portanto, "só será [serão] um ambiente alfabetizador se incorporar [incorporarem] a atualidade cultural da criança e sua história que contém o presente e o passado de seu grupo sociocultural" (p.148).

Percebi que no CAp-UERJ as mesas dos alunos e alunas são arrumadas em grupos de cinco ou quatro ou em formato semicircular, remetendo-nos a uma prática pedagógica dialógica. Nas estantes, há uma enorme quantidade de livros, gibis, revistas, enciclopédias, dentre outros textos, e cada sala tem a sua mini-biblioteca.

Essas características são realçadas pela professora Rita

Então, tem uma questão que é essa ênfase na leitura, e o trabalho de apropriação da leitura vai se dando na própria leitura, no movimento de leitura e de exploração dos textos escritos. Uma exploração que permita a essas crianças desenvolver toda uma compreensão leitora, permita também a apropriação das questões da própria língua, da escrita e do desenvolvimento da escrita. Como, também, a percepção do que é ler e escrever, da importância do ler e escrever e qual a função social da leitura e da escrita. Então o que a gente tem trabalhado é com os textos do cotidiano, com essas leituras que permeiam o cotidiano 
e então a partir daí a exploração (professora Rita, $01 / 12 / 2005)$.

Para Regina Leite Garcia (1995) aprende-se a escrever escrevendo e lendo muito. O que lêem e escrevem as crianças no dia-a-dia da sala de aula? Escrevem para quê? Por quê? As atividades de leitura e escrita propostas mobilizam desejos e interesses das crianças? Acredito que essas questões são importantes para as professoras Jaqueline e Rita que perseguem uma ação alfabetizadora subsidiada pelo que defende Smolka:

(...) o próprio processo de aquisição também vai se dando numa sucessão de momentos discursivos de interlocução e de interação. (...) Nesse sentido, a alfabetização é um processo discursivo: a criança aprende a ouvir, a entender o outro pela leitura; aprende a falar, a dizer o que quer pela escrita (2003, p.29,63)

Sabemos que há práticas alfabetizadoras que ajudam a formar leitores mais críticos e com maior autonomia na leitura e na escrita e outras que engessam a criatividade e a criticidade do leitor, levando, muitas vezes, o (a) aluno (a) a uma verdadeira aversão aos textos e, respectivamente, à leitura. Essas professoras parecem investir na formação de leitores e escritores críticos desde o início desse aprendizado.

\section{CONSIDERAÇÕES FINAIS}

Ao analisar os saberes e fazeres presentes nas narrativas, não fiz generalizações, como se as falas constituíssem uma única verdade, nem tampouco procurei contrapô-las em busca de um saber. A minha análise foi pautada nas narrativas recolhidas, portanto o foco do trabalho não foi explicitar um modelo "correto" de alfabetização, ou confirmar possíveis hipóteses. O desafio da pesquisa consistiu em tentar resgatar em suas falas os saberes e fazeres presentes em seus cotidianos escolares. Ao narrarem seus fazeres e saberes, as professoras abrem um espaço para o diálogo, para 
pensar e repensar as práticas cotidianas. "As falas do senso comum traduzem um saber. Trata-se de um saber "não sabido" sobre o qual os seus detentores não reflectem com critérios de cientificidade" ( PAIS, 2003, p. 134, grifo do autor).

Nessa ação pesquisadora optei por trabalhar as narrativas enquanto fenômeno e também enquanto método de análise, como denominado por Connelly y Clandinin (1995): Investigação narrativa. Essa escolha se deu por acreditar que os indivíduos experienciam de forma muito particular o que acontecem em suas vidas, cada um dos atores da pesquisa tem a sua história, a sua memória, que não deixa de ser coletiva mas a narrativa traz a forma como aquela pessoa compreende o que está a sua volta, como ela experienciou determinada situação e o que para ela vale a pena ser lembrado.

Dessa forma, esse estudo foi de natureza qualitativa por entender que os quadros de pesquisa abertos e flexíveis oferecem mais possibilidade de dar conta de realidades múltiplas e situações interativas, que ocorrem no dia-a-dia da sala de aula e na realização da pesquisa (PAIS, 2003, p.145). Tendo em vista que este trabalho está ligado diretamente ao cotidiano de professoras, que aparece presente em suas narrativas, de uma determinada Instituição, ele também se caracteriza como um estudo de caso.

\section{REFERÊNCIAS BIBLIOGRÁFICAS}

ARAÚJO, Mairce (2004). Ambiente Alfabetizador: a sala de aula como entre-lugar de culturas. In: GARCIA, Regina (org.). Novos olhares sobre a alfabetização. São Paulo: Cortez, p.139 -159.

BAKHTIN, Mikhail (2003). Estética da criação verbal. São Paulo: Martins Fontes. 
CONNELlY, F, Michael; CLANDININ, D. Jean (1995). Relatos de Experiencia e Investigación Narrativa. In: LARROSA, Jorge et al. (Org.). Déjame que te Cuente. Barcelona: Editora Laertes, p.11 -59.

FREIRE, Paulo (1997). Pedagogia da autonomia. São Paulo: paz e terra.

GARCIA, Regina Leite (2004). Novos olhares sobre a alfabetização.São Paulo: Editora Cortez.

(1995). Cartas Londrinas e de outros lugares sobre o lugar da educação. Rio de Janeiro:Relume Dumará.

NAJMANOVICH, Deise (2001). O sujeito encarnado.Rio de Janeiro: DP\&A.

NÓVOA, A. (1995). Formação de professores e profissão docente. Lisboa: Publicações Dom Quixote.

RIBEIRO, Leila B. Narrativas Informacionais: cinema e informação como inovações modernas. 2005. Rio de Janeiro. Tese (Doutorado) Escola de Comunicação da Universidade Federal do Rio de Janeiro/Instituto Brasileiro em Informação Científica e Tecnológica, 2005.

PAIS, José (2003). Vida Cotidiana-Enigmas e revelações. São Paulo: Cortez.

PERÉZ, Carmen Lúcia Vidal (2003). Professoras alfabetizadoras: Histórias plurais, práticas singulares. Rio de Janeiro: DP\&A.

PÉREZ GÓMEZ, Angel (2001). A cultura escolar na sociedade neoliberal.Porto Alegre: Artmed.

SAMPAIO, Carmen, S. Aprendi a ler (...) quando eu misturei todas aquelas letras ali... 2003. 281f. Tese (Doutorado) Faculdade de Educação da UNICAMP, Campinas, 2003

SMOLKA, Ana Luiza Bustamante (2003). A criança na fase inicial da escrita: a alfabetização como processo discursivo.São Paulo: editora Cortez.

TEBEROSKY, Ana (2005). Debater e opinar estimulam a leitura e a escrita. Nova escola, edição 187. nov. 
VYGOTSKY, L.S. (1999). Pensamento e linguagem.São Paulo: Martins Fontes.

\section{Autora}

Isis Flora Santos - Universidade Federal Fluminense - UFF

Contato: isisflora@terra.com.br

\section{Como citar este artigo:}

SANTOS, Isis Flora. Narrativas: as falas da experiência - colaboração para a formação de professores no mundo lusófono. Revista ACOALFAplp: Acolhendo a Alfabetização nos Países de Língua portuguesa, São Paulo, ano 4, n. 7, 2009. Disponível em: <http://www.acoalfaplp.net>. Publicado em: setembro 2009.

Recebido em fevereiro de 2009. / Aprovado em abril de 2009. 